\title{
Real-time Processing in Reading Sentence Comprehension for Normal Adult Individuals and Persons with Aphasia
}

\begin{abstract}
The current study investigated whether persons with aphasia (PWA) exhibit longer processing times than normal adult individuals (NAI) in conditions that require more complex linguistic integration, using a self-paced word-by-word sentence reading method. The word-category comparison revealed that PWA show significantly longer reading times for nouns with high integration cost than for determiners with least linguistic integration cost compared to NAI. These results are consistent with the findings that PWA exhibit language-processing difficulties at points of high processing demand (Caplan, et al., 1985; McNeil, 1982).
\end{abstract}

\section{Introduction}

Individuals with aphasia have difficulty integrating linguistic material in order to produce and comprehend words and sentences. This difficulty is due either to languagespecific computational deficits (Grodzinsky, 2000) or to a language-specific impairment in the processing resources needed to carry out those operations (Caplan, et al., 1985; McNeil, 1982). These linguistic deficits often appear as an over-additive degradation of performance for persons with aphasia (PWA) compared to unimpaired individuals. This difference has been shown in the most challenging conditions, such as those revealed under dual tasks, increased short term memory load, and for processing more challenging language structures such as object relative clauses (e.g., Caplan, et al., 2007).

However, these effects have traditionally been shown using non-standardized tools that have little or no psychometric validation, often leaving it unclear whether the nonstandardized tools themselves are responsible for the reported patterns. Furthermore, these differences between aphasic and unimpaired individuals have been shown primarily for very complex and low-frequency linguistic forms. Less evident is whether these differences might also be found for simpler, higher-frequency forms, especially structures that do not have specific linguistic properties that are the putative locus of the aphasic language deficits (viz. Grodzinsky, 2000). Furthermore, it is unknown whether the deficits in carrying out linguistic operations by PWA are reflected in real-time processing, or appear only in tasks that measure performance off-line.

The current study investigated whether PWA exhibit difficulty in integrating linguistic material during real-time processing, using a computerized adaptation of a wellvalidated measure of language comprehension; the self-paced word-by-word reading version of the Computerized Revised Token Test (CRTT- $\mathrm{R}_{\mathrm{wf}}$ ) (McNeil et al., 2008). In the CRTT- $_{\mathrm{wf}}$, sentence stimuli consist of verbs ('touch' or 'put') followed by articles ('the'), adjectives related to colors ('red, blue, green, black, white') or size ('big' or 'little'), and nouns ('square' or 'circle'). These simple sentence constructions are well-controlled for word frequency and length across the stimuli, and the lexical items are of higher frequency than those typically used in non-standardized assessment tools.

It is assumed that the nouns in the CRTT- $\mathrm{R}_{\mathrm{wf}}$ are the place at which the information regarding the color, size and shape of a target token must be integrated (Gibson, 1998). Therefore, nouns are the words that impose the greatest linguistic integration burden 
compared to other words in the sentence. In contrast, the definite article ('the') is assumed to be the word that requires the least integration cost in the CRTT- $\mathrm{R}_{\mathrm{wf}}$. Furthermore, the number of adjectives padded into the noun phrase is controlled in the CRTT- $\mathrm{R}_{\mathrm{wf}}$, and it is assumed that the nouns preceded by two adjectives have a greater integration cost than those with a single adjective. The current study investigated whether PWA would show over-additive processing times compared to normal adult individuals (NAI) as a function of sentence complexity as determined by the word-category and adjectival padding.

\section{Methods}

Sixty individuals (30 NAI and 30 PWA) participated in the study. The ages of the NAI ranged from 38 to 83 (mean=65, $S D=12$ ). They passed hearing, vision, memory, and language screens, and reported no history of communication, neurological, or psychiatric disorder. The PWA ranged in age from 38 to 90 (mean=63, $S D=13$ ) and were included based on their performance on the Porch Index of Communicative Ability (PICA) (Porch, 2001), the auditory CRTT (McNeil et al., 2008) and on the immediate and delayed language recall task of the Assessment Battery of Communication in Dementia (Bayles \& Tomoeda, 1993). In addition, all participants were given the Reading Comprehension Battery for Aphasia (RCBA-2) ( $2^{\text {nd }}$ Edition) (LaPointe \& Horner, 1998). Biographical and selection data are summarized for the PWA in Table 1 and for the NAI in Table 2.

All of the participants completed the CRTT- $\mathrm{R}_{\mathrm{wf}}$ reading sentence comprehension task whereby stimuli appear on the touchscreen in a self-paced, word-by-word format with each previous word disappearing with the onset of the following word. Reading times (RT) for each word are recorded on the computer and made available for statistical analyses.

\section{Results}

When two-part commands were presented in the CRTT- $\mathrm{R}_{\mathrm{wf}}$, RTs were analyzed only for the first token, given that the $2^{\text {nd }}$ token is likely to be confounded with possible sentence wrap-up effects. A three-way ANOVA was computed with the group (PWA vs. NAI) as a between-subject factor and the word-category (Determiner vs. Noun) and adjective padding (1-adjective vs. 2-adjectives) as within-subject factors.

There were significant main effects for the group, with longer RTs $(p<.000)$ for PWA than NAI, for word-category $(p<.000)$, with longer RTs in nouns than determiners, and for adjective padding $(p<.000)$, with longer RTs in the 2-adjective than the 1-adjective padding condition. There was a significant $(p<.005)$ word-category by group interaction with longer RTs observed for nouns than for determiners in PWA compared to NAI; and a significant $(p<.000)$ adjective padding by word-category interaction, with longer RTs for nouns than determiners in the 2-adjective compared to the 1-adjective padding condition. RTs are plotted for subtest 1 through 8 in Figure 1.

\section{Discussion}

The current study investigated whether PWA would exhibit longer processing times than NAI in conditions that require more complex linguistic integrations. Results revealed that PWA showed significantly longer RTs in nouns with high integration cost than in determiners with low integration cost compared to NAI, indicating that PWA show an over-additive effect of complexity even in sentences with simple syntactic structure and 
high frequency words. These results are consistent with the findings that PWA exhibit language-processing difficulty at points of high processing demand (Caplan, et al., 1985; McNeil, 1982), but is unexpected if aphasic language deficits are specific to certain types of complex language stimuli (Grodzinsky, 2000). However, adjective padding did not tax processing sufficiently in PWA to reveal an over-additive degradation of performance compared to those evidenced in NAI. This factor did however serve as a complexity factor across the groups.

\section{Acknowledgements}

This research was supported by the Department of Veteran Affairs, Veterans Health Administration, Rehabilitation Research and Development Service (award \#C4074X to Malcolm R McNeil).

\section{References}

Bayles, K., \& Tomoeda, C. (1993) Arizona Battery for Communication Disorders of Dementia. Tucson, AZ: Canyonlands Publishing

Caplan, D., Baker, C., \& Dehaut, F. (1985). Syntactic determinants of sentence comprehension in aphasia. Cognition, 21, 117-175.

Caplan, D., Waters, G. S., DeDe, G., Michaud, J., \& Reddy, A. (2007). A study of syntactic processing in aphasia I: Behavioral (psycholinguistic) aspects. Brain and Language, 101, 103-150.

Gibson, E. (1998). Linguistic complexity: locality of syntactic dependencies. Cognition, 68, 1-76.

Grodzinsky, Y. (2000). The neurology of syntax: language use without Broca's area. Behavioral and Brain Sciences, 23, 1-71.

LaPointe, L. \& Horner, J. (1998). Reading Comprehension Battery for Aphasia-2 (2nd edition), Austin, TX: Pro-Ed.

McNeil, M. R. (1982). The nature of aphasia in adults. In N. J. Lass, L. McReynolds, J. McNeil, M.R., Sung, J.E., Pratt, S.R., Szuminsky, N., Kim, A., Ventura, M., Fassbinder, W., Fossett, T., Doyle, P., \& Musson, N. (2008). Concurrent validation of the Computerized Revised Token Test (CRTT) and three experimental reading CRTT-R versions in normal elderly individuals and persons with aphasia. Presented at Clinical Aphasiology Conference, Teton Village, WY.

Porch, B.E. (2001). The Porch Index of Communicative Ability (3rd Edition). Palo Alto, CA: Consulting Psychologists Press. 
Table 1. Descriptive and criteria measures for the PWA

\begin{tabular}{|c|c|c|c|c|c|c|}
\hline PWA & $\begin{array}{l}\text { PICA } \\
\text { (\%ile) } \\
\end{array}$ & $\begin{array}{l}\text { RCBA } \\
(\mathrm{OA}) \\
\end{array}$ & $\begin{array}{c}\text { Age } \\
\text { (Yrs.) } \\
\end{array}$ & $\begin{array}{c}\text { Education } \\
\text { (Yrs.) }\end{array}$ & MPO & Gender \\
\hline 1 & 73 & 178 & 63 & 14 & 456 & $\mathrm{~F}$ \\
\hline 2 & 76 & 172 & 66 & 12 & 192 & M \\
\hline 3 & 49 & 158 & 70 & 12 & 96 & $\mathrm{~F}$ \\
\hline 4 & 66 & 181 & 72 & 14 & 444 & $\mathrm{~F}$ \\
\hline 5 & 72 & 178 & 60 & 16 & 24 & $\mathrm{M}$ \\
\hline 6 & 86 & 185 & 66 & 13 & 25 & $\mathrm{~F}$ \\
\hline 7 & 52 & 179 & 45 & 16 & 13 & $\mathrm{~F}$ \\
\hline 8 & 84 & 184 & 49 & 16 & 71 & $\mathrm{~F}$ \\
\hline 9 & 66 & 186 & 61 & 16 & 15 & $\mathrm{~F}$ \\
\hline 10 & 76 & 179 & 65 & 12 & 201 & M \\
\hline 11 & 53 & 160 & 38 & 14 & 25 & $\mathrm{M}$ \\
\hline 12 & 57 & 166 & 76 & 12 & 564 & $\mathrm{~F}$ \\
\hline 13 & 88 & 187 & 43 & 14 & 91 & $\mathrm{M}$ \\
\hline 14 & 69 & 174 & 62 & 16 & 60 & M \\
\hline 15 & 89 & 190 & 53 & 18 & 88 & $\mathrm{~F}$ \\
\hline 16 & 71 & 176 & 69 & 10 & 453 & $\mathrm{~F}$ \\
\hline 17 & 71 & 162 & 59 & 12 & 24 & $\mathrm{M}$ \\
\hline 18 & 88 & 182 & 56 & 18 & 31 & $\mathrm{M}$ \\
\hline 19 & 29 & 86 & 83 & 12 & 30 & F \\
\hline 20 & 69 & 166 & 40 & 18 & 12 & $\mathrm{M}$ \\
\hline 21 & 89 & 190 & 51 & 18 & 139 & $\mathrm{~F}$ \\
\hline 22 & 83 & 189 & 90 & 12 & 58 & M \\
\hline 23 & 59 & 184 & 63 & 18 & 46 & M \\
\hline 24 & 70 & 157 & 70 & 12 & 29 & $\mathrm{~F}$ \\
\hline 25 & 76 & 179 & 82 & 16 & 106 & M \\
\hline 26 & 41 & 102 & 77 & 12 & $\mathrm{MD}$ & $\mathrm{M}$ \\
\hline 27 & 66 & 185 & 64 & 18 & 68 & $\mathrm{M}$ \\
\hline 28 & 48 & 175 & 75 & 12 & 180 & $\mathrm{M}$ \\
\hline 29 & 26 & 124 & 69 & 12 & 59 & M \\
\hline 30 & 66 & 175 & 49 & 14 & 6 & $\mathrm{M}$ \\
\hline Mean & 66.93 & 170 & 63 & 14 & 124 & (F; 13/ M; 17) \\
\hline SD & 16.80 & 25 & 13 & 2 & 155 & \\
\hline
\end{tabular}


Table 2. Descriptive and criteria measures for the NAI

\begin{tabular}{|c|c|c|c|c|c|}
\hline ID & $\begin{array}{l}\text { PICA } \\
\text { (\%ile) }\end{array}$ & $\begin{array}{c}\text { RCBA } \\
(\mathrm{OA})\end{array}$ & $\begin{array}{c}\text { Age } \\
\text { (Yrs.) }\end{array}$ & $\begin{array}{l}\text { Education } \\
\text { (Yrs.) }\end{array}$ & Gender \\
\hline 1 & 10 & 179 & 55 & 11 & $\mathrm{~F}$ \\
\hline 2 & 55 & 190 & 74 & 18 & M \\
\hline 3 & 27 & 186 & 71 & 14 & M \\
\hline 4 & 30 & 189 & 59 & 13 & M \\
\hline 5 & 4 & 186 & 50 & 12 & M \\
\hline 6 & 10 & 188 & 77 & 16 & M \\
\hline 7 & 20 & 186 & 66 & 14 & M \\
\hline 8 & 25 & 187 & 70 & 12 & M \\
\hline 9 & 12 & 187 & 64 & 18 & M \\
\hline 10 & 95 & 188 & 69 & 12 & $\mathrm{~F}$ \\
\hline 11 & 5 & 189 & 68 & 18 & F \\
\hline 12 & 7 & 189 & 56 & 12 & F \\
\hline 13 & 2 & 183 & 77 & 12 & $\mathrm{M}$ \\
\hline 14 & 25 & 190 & 64 & 14 & $\mathrm{~F}$ \\
\hline 15 & 7 & 183 & 77 & 12 & $\mathrm{~F}$ \\
\hline 16 & 4 & 188 & 70 & 12 & M \\
\hline 17 & 3 & 187 & 76 & 14 & F \\
\hline 18 & 25 & 188 & 71 & 16 & M \\
\hline 19 & 25 & 188 & 83 & 18 & $\mathrm{~F}$ \\
\hline 20 & 10 & 187 & 81 & 14 & $\mathrm{M}$ \\
\hline 21 & 4 & 189 & 78 & 12 & $\mathrm{M}$ \\
\hline 22 & 22 & 172 & 71 & 12 & $\mathrm{M}$ \\
\hline 23 & 22 & 189 & 52 & 18 & M \\
\hline 24 & 20 & 190 & 76 & 12 & $\mathrm{~F}$ \\
\hline 25 & 3 & 181 & 42 & 12 & M \\
\hline 26 & 35 & 188 & 54 & 18 & F \\
\hline 27 & 35 & 189 & 38 & 13 & F \\
\hline 28 & 58 & 190 & 56 & 18 & F \\
\hline 29 & 2 & 190 & 50 & 18 & M \\
\hline 30 & 7 & 189 & 48 & 13 & M \\
\hline Mean & 20.30 & 187 & 65 & 14 & (F;12/M; 18) \\
\hline SD & 20.42 & 4 & 12 & 3 & \\
\hline
\end{tabular}


Figure 1. Reading times on each word category for both groups in subtext 1 through 8
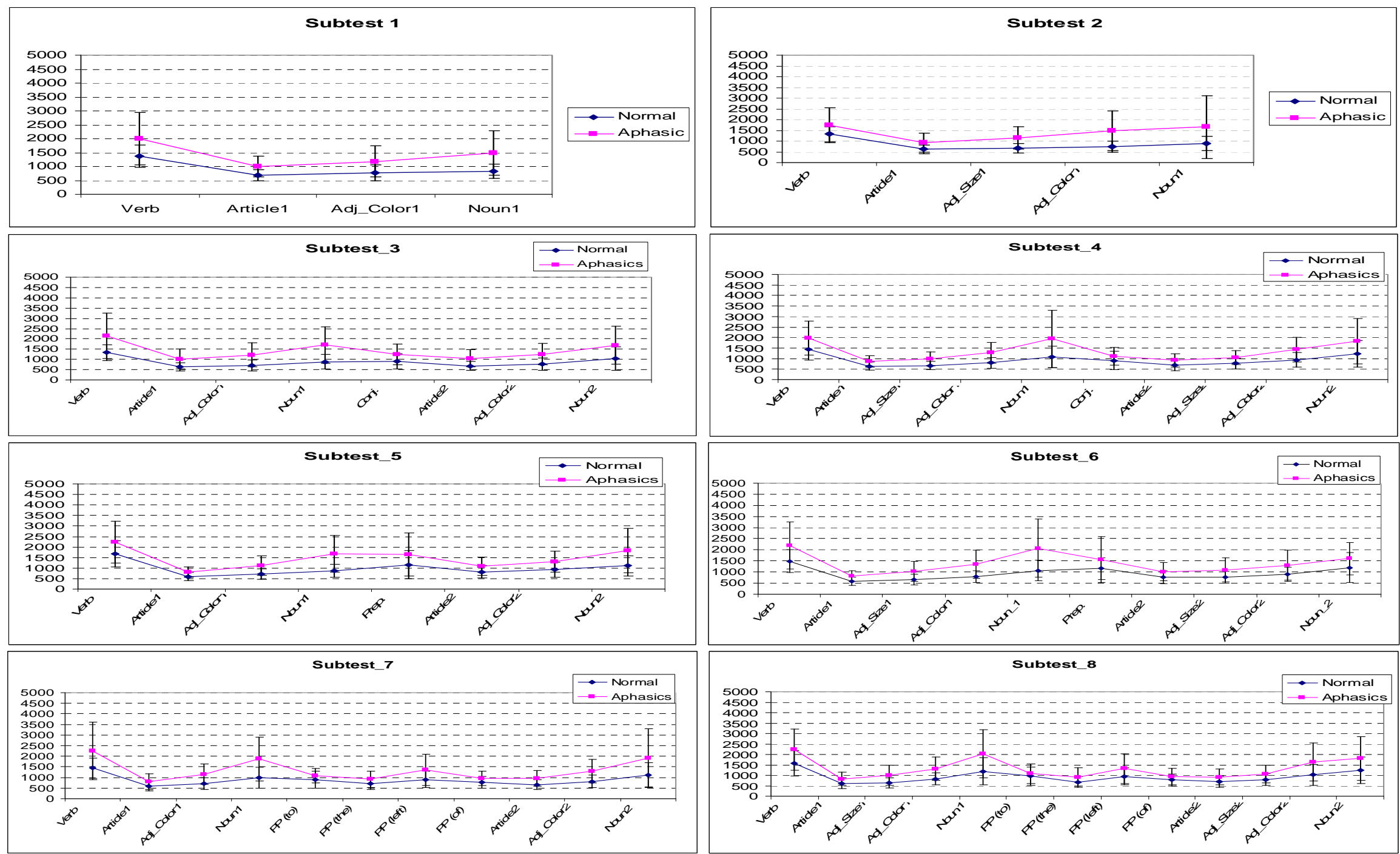

6 